\title{
Densidade de plantio e genótipos de tomateiro cereja em sistema fechado de cultivo em substrato
}

\author{
Roberta MN Peil; Antonio AR Albuquerque Neto; Cesar V Rombaldi \\ 'UFPEL-FAEM, C. Postal 354, 96010-900 Pelotas-RS; rmpeil@ufpel.tche.br; agroquerque@gmail.com; cesarvrf@ufpel.edu.br
}

\begin{abstract}
RESUMO
O cultivo de tomateiro em sistemas fechados (com reutilização da solução drenada) é essencial para reduzir as perdas de água e nutrientes e a contaminação ambiental, mas escassas são as informações na literatura. $\mathrm{O}$ objetivo foi avaliar o efeito de densidades de cultivo $\left(2,9 ; 3,9 ; 4,7 ; 5,9\right.$ e 7,8 plantas $\left.\mathrm{m}^{-2}\right)$ no crescimento, na produtividade e na qualidade de frutos de dois genótipos de tomateiro cereja ('Cereja Vermelho' e 'Flavor Top') cultivados em casca de arroz com sistema fechado de circulação da solução nutritiva. Foram avaliados a produção e partição da matéria seca de hastes, folhas e frutos; número, massa fresca média e produtividade de frutos; teor de sólidos solúveis e concentração de fitoquímicos (carotenóides, compostos fenólicos totais e capacidade antioxidante). 'Cereja Vermelho' apresentou maior alocação de fotoassimilados nos frutos, crescimento e produtividade e 'Flavor Top' apresentou maior concentração de sólidos solúveis, maior concentração de fenóis e capacidade antioxidante. $\mathrm{O}$ aumento da densidade de plantio reduziu o crescimento individual das plantas sem afetar a partição de matéria seca, aumentando a produtividade por unidade de área. As densidades de plantio de 5,9 e 7,8 plantas $\mathrm{m}^{-2}$ são as mais adequadas, respectivamente, para 'Cereja Vermelho' e 'Flavor Top'.
\end{abstract}

Palavras-chave: Solanum lycopersicon, cultivo protegido, solução recirculante, crescimento, produtividade, fitoquímicos.

\begin{abstract}
Plant density and cherry tomato genotypes in closed substrate growing system

The cultivation of cherry tomato in closed substrate systems (which promote reuse of the drained solution) is fundamental in order to reduce water and fertilizer waste and environmental pollution. However, the literature background is scarce. This work aimed to establish the influence of different plant densities $(2.9 ; 3.9 ; 4.7 ; 5.9$ and 7.8 plants $\mathrm{m}^{-2}$ ) on growth, yield and fruit quality of two cherry tomato genotypes ('Cereja Vermelho' and 'Flavor Top') grown in rice husk closed growing system. Dry matter production and partitioning of stems, leaves and fruits; number of fruits, average weight and yield; fruit soluble solids content and phytochemicals content (carotenoids, total phenolic compounds and antioxidant capacity) were evaluated. 'Cereja Vermelho' presented higher assimilates allocation into the fruits, higher growth and fruit yield. 'Flavor Top' presented higher soluble solids content, phenolics compounds and antioxidant capacity. The increasing of plant density decreased individual plant growth, had no effect on dry matter partitioning and increased fruit yield per square meter. The plant densities of 5.9 and 7.8 plants $\mathrm{m}^{-2}$ are the most proper for 'Cereja Vermelho' and 'Flavor Top', respectively.
\end{abstract}

Keywords: Solanum lycopersicon, protected cultivation, recirculating solution, plant growth, yield, phytochemicals.

\section{(Recebido para publicação em 19 de setembro de 2013; aceito em 16 de abril de 2014) (Received on September 19, 2013; accepted on April 16, 2014)}

$\mathrm{U}$ ma expansão significativa na produção de hortaliças de frutos em sistemas abertos de cultivo em substrato, especialmente do tomateiro, vem ocorrendo nos últimos anos. Esses sistemas caracterizam-se pela ausência de recirculação da solução nutritiva, sendo lixiviado o excedente à capacidade de retenção do substrato (Andriolo et al., 2003). Entretanto, por questões econômicas e ambientais, os sistemas fechados, com coleta e reutilização da solução nutritiva drenada (Gimenez et al., 2008), são a tendência para o cultivo de hortaliças.

Nos sistemas de cultivo em substratos, estudos têm sido feitos com materiais orgânicos de fácil obtenção e passíveis de reciclagem. A casca de arroz é um abundante subproduto da indústria arrozeira no Brasil, que tem mostrado resultados promissores na forma carbonizada (Peil et al., 1994; Carrijo et al., 2004) e in natura (Duarte et al., 2008a, 2008b; Strassburger et al., 2011).

O cultivo em substrato é realizado sob ambiente protegido, sendo que o investimento na sua implantação é relativamente dispendioso. Assim, estudos sobre a ecofisiologia e o manejo de culturas, que venham a incrementar a produtividade e elucidar a dinâmica de crescimento são essenciais.

O crescimento é definido pela produção e partição de matéria seca entre os diferentes órgãos da planta, sendo determinado pela relação entre fonte $\mathrm{e}$ drenos (Peil \& Gálvez, 2005). Os principais órgãos fonte de uma planta são as folhas maduras (Taiz \& Zeiger, 2009). Os frutos, quando em desenvolvimento, são os principais órgãos dreno (Taiz \& Zeiger, 2009). O equilíbrio entre o fornecimento, fonte, e a demanda de fotoassimilados, drenos, é fundamental para garantir um adequado crescimento e alta produtividade (Peil \& Gálvez, 2005).

A área foliar de uma planta constitui sua base para a fotossíntese, podendo ser aumentada por meio de maior densidade de plantas (Cockshull et al., 1992). A variação da densidade de cultivo é de fácil adoção para manejar a relação fonte/ dreno e o balanço de assimilados entre os órgãos vegetativos e os frutos (Peil \& Gálvez, 2005) e, consequentemente, 
alterar o crescimento da cultura. A elevada produtividade em plantios adensados é devida ao aumento da interceptação da luz fotossinteticamente ativa e da fotossíntese do dossel, que estimula o crescimento da cultura, aumentando o total de assimilados ao crescimento dos frutos.

No tomateiro, além do número de plantas por unidade de área, o número de frutos por planta e a massa média dos frutos estão diretamente relacionados à produtividade (Papadopoulos \& Pararajasingham, 1997). Com o adensamento do cultivo, não há variação no número de frutos por planta, mas sim redução na massa média dos frutos e aumento na produtividade por área (Carvalho \& Tessarioli Neto, 2005). Entretanto, tais relações são influenciadas pela época, local e genótipo (Papadopoulos \& Pararajasingham, 1997).

Estudos sobre essas relações têm sido realizados com tomateiros do grupo salada e sob diferentes condições locais de radiação (Seleguini et al., 2002). As respostas agronômicas podem ser diferentes mesmo entre genótipos pertencentes a um mesmo grupo comercial, conforme mostraram Genúncio et al. (2006). Esses autores encontraram diferenças no acúmulo de matéria seca e fresca, na produção, no tamanho médio dos frutos e nos teores de sólidos solúveis da polpa em três cultivares de tomateiro do tipo salada. Entretanto, não há informações sobre essas relações e sobre diferenças entre grupos para tomate do tipo cereja, em que a força de dreno individual dos frutos é menor. Aliado a isso, o tomate apresenta valor nutricional considerável se comparado a outras oleráceas de fruto, como melancia e morango (Kalogeropoulos et al., 2012). Entretanto, há poucas informações sobre a produção e o acúmulo de fitoquímicos, que são compostos do metabolismo vegetal secundário essenciais à dieta humana, juntamente com os minerais (Lasheras et al., 2000) e podem variar entre as espécies (Luthria et al., 2006).

Assim, o objetivo foi estabelecer a influência de diferentes densidades de cultivo sobre o crescimento, a produtividade e a qualidade de frutos de dois genótipos de tomateiro cereja cultivados em casca de arroz com sistema fechado.

\section{MATERIAL E MÉTODOS}

O experimento foi conduzido entre outubro e dezembro de 2009 na Universidade Federal de Pelotas, localizada no município de Capão do Leão-RS (31 ${ }^{\circ} 52^{\prime} \mathrm{S}, 5^{\circ} 21^{\prime} \mathrm{O}$, altitude $13 \mathrm{~m}$ ). O clima da região, segundo a classificação de Köppen, é do tipo Cfa (temperado úmido com verão quente) (Mota et al., 1986).

Dois fatores experimentais foram estudados: densidade de plantio, com cinco níveis $(2,9 ; 3,9 ; 4,7 ; 5,9$ e 7,8 plantas $\mathrm{m}^{-2}$, correspondentes aos espaçamentos entre plantas na linha de 0,$40 ; 0,30 ; 0,25 ; 0,20$ e $0,15 \mathrm{~m}$, respectivamente) e genótipos com dois níveis (Cereja Vermelho Feltrin ${ }^{\circledR}$ e Flavor Top). O genótipo Flavor Top não é comercial e foi desenvolvido pelo Prof. César Rombaldi, sendo selecionado para este estudo devido à alta concentração de fitoquímicos. Assim, constituiu-se um experimento com 10 tratamentos e seis repetições dispostas em blocos ao acaso com parcelas subdivididas, sendo o fator densidade alocado na parcela e o fator genótipo na subparcela. A unidade experimental correspondeu a um saco plástico contendo 5 litros de casca de arroz in natura e uma planta.

$\mathrm{O}$ experimento foi realizado em estufa agrícola modelo teto em arco, de estrutura metálica (10 m de largura; 21 $\mathrm{m}$ de comprimento; 4,5 m de altura máxima; 3,5 $\mathrm{m}$ de pé direito), disposta no sentido Norte-Sul e coberta com filme de polietileno de baixa densidade de 150 $\mu \mathrm{m}$ de espessura. $\mathrm{O}$ solo apresentava-se nivelado e coberto com filme de polietileno dupla face, branco e preto, de 200 $\mu \mathrm{m}$ de espessura. Durante o período de execução do experimento, o manejo da temperatura e das trocas gasosas com o exterior foi realizado através da ventilação natural, mediante abertura e fechamento das janelas laterais e portas da casa de vegetação.

Realizou-se a semeadura dos genótipos dos tomateiros de crescimento indeterminado, em bandejas plásticas preenchidas com vermiculita expandida. Posteriormente, quando as plantas apresentavam três folhas definitivas, foram repicadas individualmente para cubos de

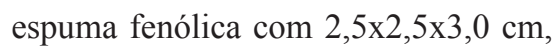
previamente lavados, onde permaneceram de 03/09 a 02/10/2009. Os cubos foram mantidos em quadros de irrigação com uma lâmina de $1 \mathrm{~cm}$ de solução nutritiva até as plantas alcançarem o estádio adequado para o transplante. Nessa fase, foi utilizada a solução nutritiva recomendada por Rocha et al. (2010) para a cultura do tomateiro cereja na concentração de $50 \%$, com condutividade elétrica de $0,9 \mathrm{dS} \mathrm{m}^{-1}$.

O experimento foi conduzido no período de $3 / 10$ a 29/12/2009. As mudas com 10 folhas definitivas foram transplantadas individualmente para sacos plásticos, contendo 5 litros de casca de arroz in natura [seguindo recomendação de Peil et al. (1994)], perfurados na base, a fim de promover a drenagem da solução nutritiva excedente. O sistema foi do tipo fechado e constituído por 12 canais de madeira de $7,5 \times 0,35 \mathrm{~m}$, com declividade de $2 \%$, internamente revestidos com filme de polietileno dupla face preto e branco. Os canais foram dispostos em 6 linhas duplas, com caminhos de 1,2 $\mathrm{m}$ e distância entre linhas simples de 0,5 m. Após a colocação dos sacos nos canais, o plástico de revestimento era fechado para minimizar o aquecimento da solução nutritiva e evitar a proliferação de algas.

A solução nutritiva foi armazenada em reservatório com capacidade de 1000 $\mathrm{L}$, que estava posicionado na extremidade da cota mais baixa do sistema, sendo conduzida aos canais de cultivo por um sistema de motobomba, tubulações de PVC de $1 / 2$ polegada e tubos gotejadores de polietileno. A solução nutritiva foi fornecida a cada planta por meio de um gotejador com vazão de $15 \mathrm{~L} \mathrm{~h}^{-1}$, posicionado na parte central do saco de cultivo. A vazão média diária por gotejador foi de 1,5 L planta dia ${ }^{-1}$, volume dividido em 6 turnos de irrigação de 1 minuto, programados através de um temporizador. A solução drenada foi conduzida até o reservatório através dos canais coletores, conforme metodologia já empregada com êxito para o cultivo do meloeiro (Duarte et al., 2008a, 2008b) e da abobrinha italiana (Strassburger et al., 2011), ambos empregando casca de arroz in natura como substrato.

A solução nutritiva foi a mesma 
utilizada para produção de mudas, mas na concentração de 100\% (Rocha et al., 2010). A solução apresentou a seguinte composição de macronutrientes (em mmol L-1): 14,0 de $\mathrm{NO}_{3}^{-} ; 1,15$ de $\mathrm{H}_{2} \mathrm{PO}_{4}^{-} ; 1,75$ de $\mathrm{SO}_{4}^{-2} ; 1,15 \mathrm{de} \mathrm{NH}_{4}^{+}$; 7,0 de $\mathrm{K}^{+} ; 3,5$ de $\mathrm{Ca}^{+2} ; 1,75$ de $\mathrm{Mg}^{+2}$. A composição de micronutrientes (em mg $\mathrm{L}^{-1}$ ) foi: 3,0 de Fe; 0,5 de Mn; 0,05 de Zn; 0,15 de B; 0,02 de Cu e 0,01 de Mo. A condutividade elétrica foi mantida em $1,8 \mathrm{dS} \mathrm{m}^{-1} \mathrm{e}$, quando este valor diminuía ou aumentava na ordem de $15 \%$, era feita a sua correção, através de soluções estoques concentradas, ou de água, respectivamente. $\mathrm{O} \mathrm{pH}$ foi mantido entre 5,5 e 6,5 , através da adição de solução de correção à base de hidróxido de potássio $(\mathrm{KOH} 1 \mathrm{~N})$ ou ácido sulfúrico $\left(\mathrm{H}_{2} \mathrm{SO}_{4} 1 \mathrm{~N}\right)$.

As plantas foram conduzidas com haste única, fazendo-se a desbrota das hastes laterais periodicamente. A poda apical da haste primária foi realizada duas folhas acima da emissão da $10^{\mathrm{a}}$ inflorescência. O tutoramento foi realizado através de uma fita de ráfia presa em linha de arame disposta 3,0 m acima da linha de cultivo e sustentada pela estrutura da casa de vegetação.

Durante o período de colheita, avaliou-se o número de frutos e a produção por planta com base na massa fresca de frutos, calculando-se a produtividade por unidade de área e a massa fresca média dos frutos.

Com a finalidade de avaliar o crescimento das plantas, a matéria seca aérea acumulada foi avaliada ao final do experimento (88 dias após o transplante). As plantas foram separadas em três frações: folhas, hastes e frutos. As frações foram secas, separadamente, em estufa de ventilação forçada a $65^{\circ} \mathrm{C}$, até peso constante. Após a secagem, as diferentes frações foram pesadas em balança de precisão, obtendo-se as suas respectivas matérias secas. O material de desbrota, desfolhas e os frutos colhidos durante o processo produtivo foram acrescentados às frações correspondentes. A matéria seca total da parte aérea da planta correspondeu à soma das matérias de folhas, caules e frutos.

As análises do teor de sólidos solúveis totais foram feitas com um refratômetro manual; o teor de caro- tenóides, segundo o método descrito por Rodriguez-Amaya (1999); o teor de compostos fenólicos totais segundo Singleton \& Rossi (1965) e a capacidade antioxidante conforme Re et al. (1999).

Os dados obtidos foram submetidos à análise da variância, sendo o efeito da densidade avaliado por meio de análise de regressão e a comparação de médias do fator genótipo pelo teste de Tukey $(\mathrm{p}<0,005)$, usando o programa estatístico WinStat (Stauss, 2008).

\section{RESULTADOS E DISCUSSÃO}

As análises de variância dos resultados indicaram a existência de interação significativa entre os genótipos e as densidades de plantio para a maioria das variáveis, exceto para matéria seca (MS) de haste por planta, partição de MS entre os diferentes órgãos da planta e número de frutos por planta.

Houve diferenças significativas para a produção de MS da parte aérea total das plantas, folhas e frutos entre 'Cereja Vermelho' e 'Flavor Top' e entre as densidades estudadas dentro de cada genótipo. 'Cereja Vermelho' produziu, aproximadamente, o dobro da quantidade de MS de todos os órgãos em relação à produção de 'Flavor Top' (Figuras 1a, 1b). O aumento da densidade de plantio causou redução da produção de MS dos frutos e das hastes e, consequentemente, da parte aérea das plantas de ambos os genótipos. Os genótipos se comportaram diferentemente em relação à variação da densidade de plantio. A densidade de plantio influenciou a produção de
MS de folhas somente de 'Cereja Vermelho' (Figuras 1a). Em 'Flavor Top', este efeito não foi observado (Figura 1b). Foi constatada uma baixa produção de MS das folhas deste genótipo em todas as densidades. Assim, devido ao pequeno aparato fotossintético das plantas, a elevação da densidade não exerceu um efeito de competição entre as folhas e, portanto, não afetou a sua produção de MS.

Quanto à produção de MS aérea total da planta, 'Cereja Vermelho' apresentou melhor desempenho na menor densidade (2,9 plantas $\left.\mathrm{m}^{-2}\right)$. Para 'Flavor Top', o valor observado para essa variável na menor densidade foi semelhante ao da densidade de 3,9 plantas $\mathrm{m}^{-2}$. A partir desses valores, ocorreu um decréscimo na produção de MS (Figuras 1a, 1b).

A produção de MS das folhas foi maior para 'Cereja Vermelho' na densidade de 2,9 plantas $\mathrm{m}^{-2}$, não havendo diferenças significativas entre as demais densidades. Para 'Flavor Top', não foram observadas diferenças estatísticas entre todas as densidades (Figuras 1a, 1b).

Para ‘Cereja Vermelho’, a produção de matéria seca dos frutos na densidade de 2,9 plantas $\mathrm{m}^{-2}$ (182 $\mathrm{g}_{\text {planta-1 }}$ ) foi superior às demais. As densidades entre 3,9 e 5,9 plantas $\mathrm{m}^{-2}$ produziram valores que não diferiram estatisticamente, de 154,9 a 148,7 g planta $^{-1}$, e maiores que o observado na densidade de 7,8 plantas $\mathrm{m}^{-2}$, com 120,8 g planta ${ }^{-1}$. Para 'Flavor Top' só ocorreu diferença significativa entre os tratamentos de 2,9 plantas $\mathrm{m}^{-2}$, com 68,2 g planta $^{-1}$, e 5,9 plantas $\mathrm{m}^{-2}$, com 47,5 g planta $^{-1}$ (Figuras 1a, 1b).

Tabela 1. Partição proporcional da matéria seca entre hastes, folhas e frutos de plantas de tomateiro dos genótipos 'Cereja Vermelho' e 'Flavor Top' cultivadas em casca de arroz e sistema fechado (dry matter partitioning among stems, leaves and fruits of tomato plants genotypes 'Cereja Vermelho' and 'Flavor Top' in raw rice husk closed growing system). Pelotas, UFPel, 2009.

\begin{tabular}{lccc}
\hline \multirow{2}{*}{ Genótipos } & \multicolumn{3}{c}{ Partição de matéria seca (\%) } \\
\cline { 2 - 4 } & Hastes & Folhas & Frutos \\
\hline Cereja Vermelho & $22,9 \mathrm{~b}$ & 23,2 & $53,9 \mathrm{a}$ \\
Flavor Top & $36,9 \mathrm{a}$ & 22,9 & $40,2 \mathrm{~b}$ \\
\hline DMS & 5,5 & 4,8 & 5,9 \\
\hline
\end{tabular}

Médias seguidas de letras minúsculas diferentes nas colunas indicam diferença significativa pelo teste de Tukey $(\mathrm{p}<0,05)$; DMS: diferença mínima significativa [means followed by different letters in the column are different from each other by the Tukey test $\mathrm{p}<0.05$ ); DMS: least significant difference]. 


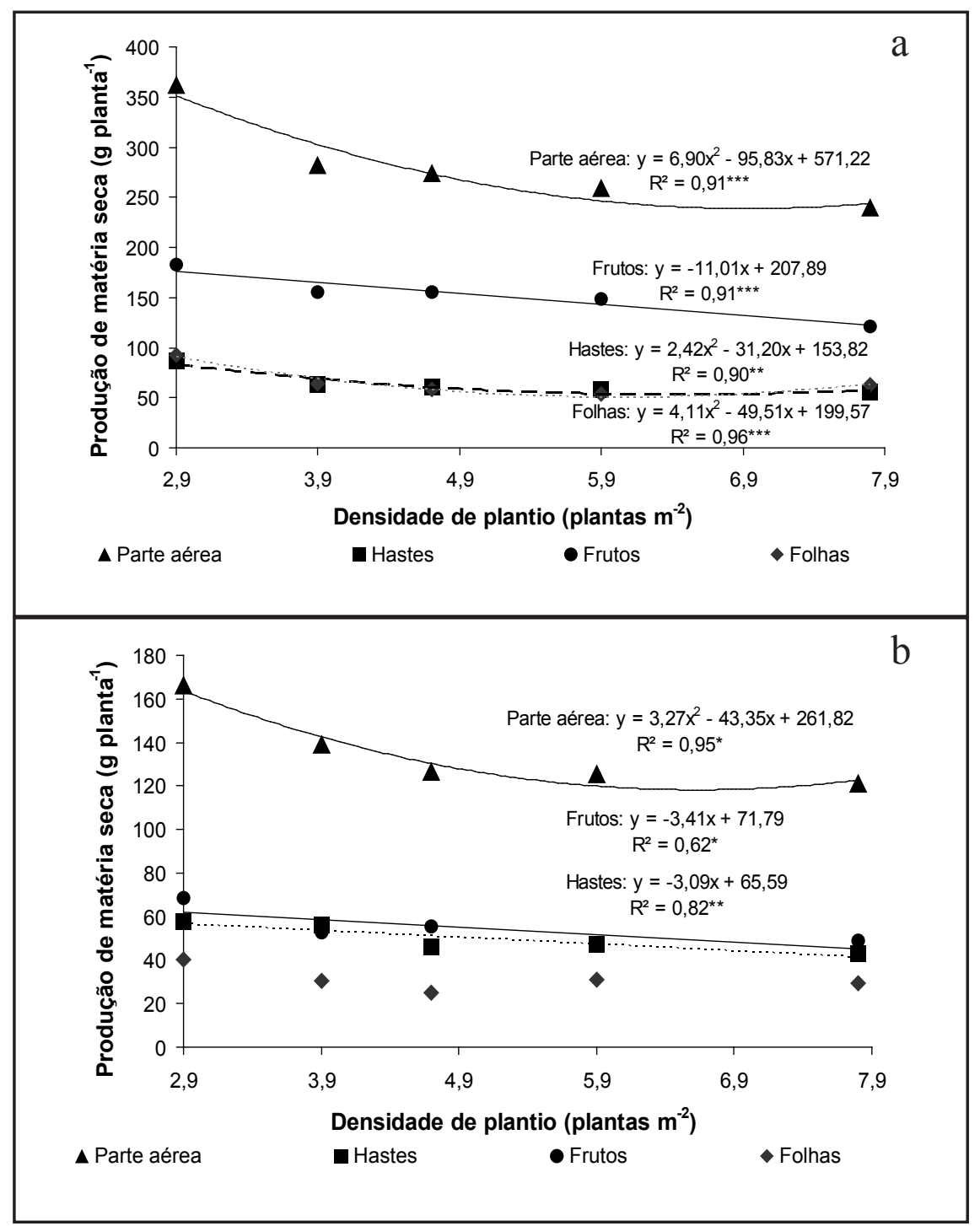

Figura 1. Produção de matéria seca da parte aérea, hastes, folhas e frutos de plantas dos genótipos de tomateiro 'Cereja Vermelho' (a) e 'Flavor Top' (b) estabelecidas em 5 densidades de plantio em substrato de casca de arroz in natura e sistema fechado [dry matter production of shoots, stems, leaves and fruits of the genotypes of tomato 'Cereja Vermelho' (a) and 'Flavor Top' (b) set at 5 plant densities in raw rice husk closed growing system]. Pelotas, UFPel, 2009.

A diminuição da produção de MS por planta com a elevação da densidade de plantio é atribuída, normalmente, à competição por radiação solar incidente que se estabelece entre as plantas, reduzindo a quantidade de radiação interceptada e, em virtude disso, a fotossíntese individual. Na menor densidade de cultivo, a planta possui mais espaço para expandir suas folhas, ocorrendo menor sobreamento mútuo. Com isso, ocorre maior interceptação de luz por planta e, consequentemente, maior crescimento individual (Andriolo et al., 2004; Papadopoulos \& Pararajasingham, 1997).
Assim, as plantas de 'Cereja Vermelho' destinaram maior proporção de MS para os frutos em detrimento das hastes. No cultivo de hortaliças fruto há uma procura por genótipos nos quais o acúmulo de fotoassimilados se concentre em maior proporção nesses órgãos, que são o objeto comercial.

Proporções diferentes de alocação da MS na parte aérea foram obtidas em trabalho sobre tomateiro Cereja Vermelho cultivado em sistema hidropônico na densidade de 3,4 plantas $\mathrm{m}^{-2} \mathrm{em}$ verão-outono (Rocha, 2009). Esse autor observou que a MS foi distribuída nas proporções de $38 \%$ nas folhas, $36 \%$ no caule e $26 \%$ nos frutos. As diferenças entre os resultados do presente trabalho e de Rocha (2009) podem ser atribuídas a vários fatores, mas, principalmente, às distintas disponibilidades radiativas dos ciclos testados (Papadopoulos \& Pararajasingham, 1997; Radin et al., 2003). No presente trabalho, realizado no ciclo de primavera, o incremento da radiação solar incidente proporcionou um maior crescimento da planta e, consequentemente, um maior índice de pegamento de frutos, o que, segundo Heuvelink (1997), favoreceria a alocação de fotoassimilados para estes órgãos em relação a um cultivo realizado no verão-outono.

Quanto ao número de frutos por planta, não houve efeito da densidade para 'Cereja Vermelho' e 'Flavor Top', que produziram, em média, 55,8 e 121,7 frutos planta ${ }^{-1}$, respectivamente.

Por outro lado, o aumento da densidade de plantio causou redução linear na massa fresca média dos frutos de 'Cereja Vermelho', que variou de $31 \mathrm{~g}$ na menor densidade até $23 \mathrm{~g}$ na densidade mais elevada (Figura 2a). Entretanto, em todas as densidades avaliadas, as massas frescas, de acordo com a classificação proposta por Fernandes et al. (2007), ajustaram-se à classe de frutos gigantes (>20 g), que apresentam maior valor potencial de mercado. Contudo, para 'Flavor Top', o efeito do aumento da densidade na redução da massa fresca média dos frutos não foi observado, cuja média foi de 4,9 g (Figura 2a). Independente da densidade avaliada, os frutos apresentaram tamanho muito reduzido, sendo considerados descartados $(<5 \mathrm{~g})$ do ponto de vista da classificação 


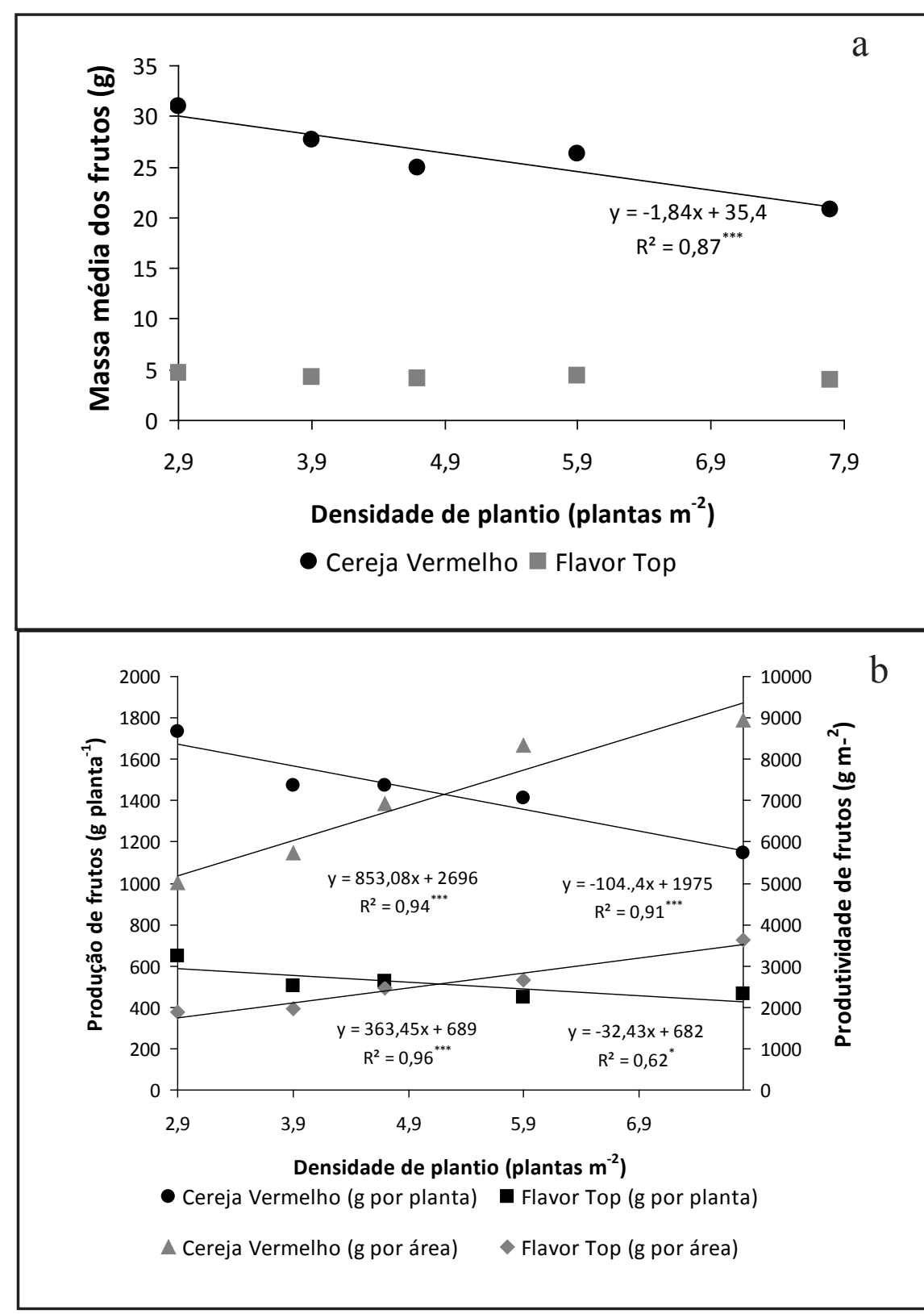

Figura 2. Massa fresca média de frutos (a); produção $\left(\mathrm{g} \mathrm{planta}^{-1}\right)$ e produtividade $\left(\mathrm{g} \mathrm{m}^{-2}\right)$ com base na massa fresca de frutos (b) dos genótipos 'Cereja Vermelho' e 'Flavor Top' estabelecidos em 5 densidades de plantio em substrato de casca de arroz in natura e sistema fechado [fruit average fresh mass (a); fruit production $\left(\mathrm{g} \mathrm{plant}^{-1}\right)$ and yield $\left(\mathrm{g} \mathrm{m}^{-2}\right)(\mathrm{b})$ of tomato genotypes 'Cereja Vermelho' and 'Flavor Top' set at 5 plant densities in raw rice husk closed growing system]. Pelotas, UFPel, 2009.

comercial proposta por Fernandes et al. (2007).

A influência da densidade de plantio sobre o tamanho dos frutos de 'Cereja Vermelho' é devida ao seu maior tamanho de frutos e, consequentemente, maior força de dreno individual dos frutos (Heuvelink, 1995). No genótipo 'Flavor Top', de frutos pequenos e, por conseguinte, pequena força de dreno, o efeito da densidade não se estabeleceu, pois o reduzido tamanho da unidade de fruto, definido pelo potencial genético, demanda poucos fotoassimilados para seu crescimento.

Para ambos os genótipos, o aumento da densidade de plantio diminuiu de forma linear a produção de frutos por planta e aumentou, também de forma linear, a produtividade por unidade de área (Figura 2b). A redução da produção de frutos por planta é atribuída ao maior sombreamento mútuo que ocorre com a elevação da densidade, o que leva a uma diminuição da área foliar da planta e, consequentemente, da interceptação de luz e da fotossíntese individuais, causando redução no crescimento e na produção de frutos (Papadopoulos \& Pararajasingham, 1997). Os resultados corroboram com Carvalho \& Tessarioli Neto (2005). Esses autores concluíram que não houve variação do número de frutos por planta do tomateiro salada, mas sim aumento na produtividade e redução na massa fresca média dos frutos à medida que se adensa o cultivo.

Com este experimento não foi alcançado o ponto de densidade crítica (Castilla, 2001) para o cultivo de tomateiro do tipo cereja. Esperava-se que, a partir de uma determinada densidade, a competição entre plantas chegasse a um nível crítico em que a redução na produção de frutos por planta não fosse mais compensada pelo aumento do número de plantas por unidade de área, havendo diminuição também na produtividade. Mas, as plantas dos dois genótipos ganharam produtividade linearmente, mesmo com alta densidade (7,8 plantas $\left.\mathrm{m}^{-2}\right)$. Entretanto, a produtividade de 'Cereja Vermelho' na densidade de 5,9 plantas $\mathrm{m}^{-2}$ foi de $8,33 \mathrm{~kg} \mathrm{~m}^{-2}$, que é 1,42 $\mathrm{kg}$ superior ao obtido com a densidade de 4,7 plantas $\mathrm{m}^{-2}$ e $0,62 \mathrm{~kg} \mathrm{~m}^{-2}$ inferior ao da densidade de 7,8 plantas $\mathrm{m}^{-2}$. Para 'Flavor Top', obteve-se 2,66 kg m-2 na densidade de 5,9 plantas $\mathrm{m}^{-2}$, cujo incremento em relação à densidade de 4,7 plantas $\mathrm{m}^{-2}$ foi de somente $0,12 \mathrm{~kg} \mathrm{~m}^{-2}$, enquanto na densidade de 7,8 plantas $\mathrm{m}^{-2}$ obteve-se $1 \mathrm{~kg} \mathrm{~m}^{-2}$ a mais $\left(3,62 \mathrm{~kg} \mathrm{~m}^{-2}\right)$.

Todavia, mesmo com o aumento linear de produtividade observado, o cultivo de plantas de tomateiro do tipo cereja, de crescimento vigoroso e com um número elevado de frutos, como foi o caso de 'Cereja Vermelho' (Figura 1a), com densidades muito elevadas não é aconselhável em virtude da dificuldade de manejo. Há que considerar-se a maior necessidade de podas e desbrotas e as dificuldades para a colheita, assim como, a maior probabilidade de incidência de doenças fúngicas e bacterianas e as consequentes dificuldades para o seu monitoramento e controle. Porém, para 'Flavor Top', que apresentou menor crescimento da planta (Figura 1b) e um número menor de frutos, pode-se empre- 


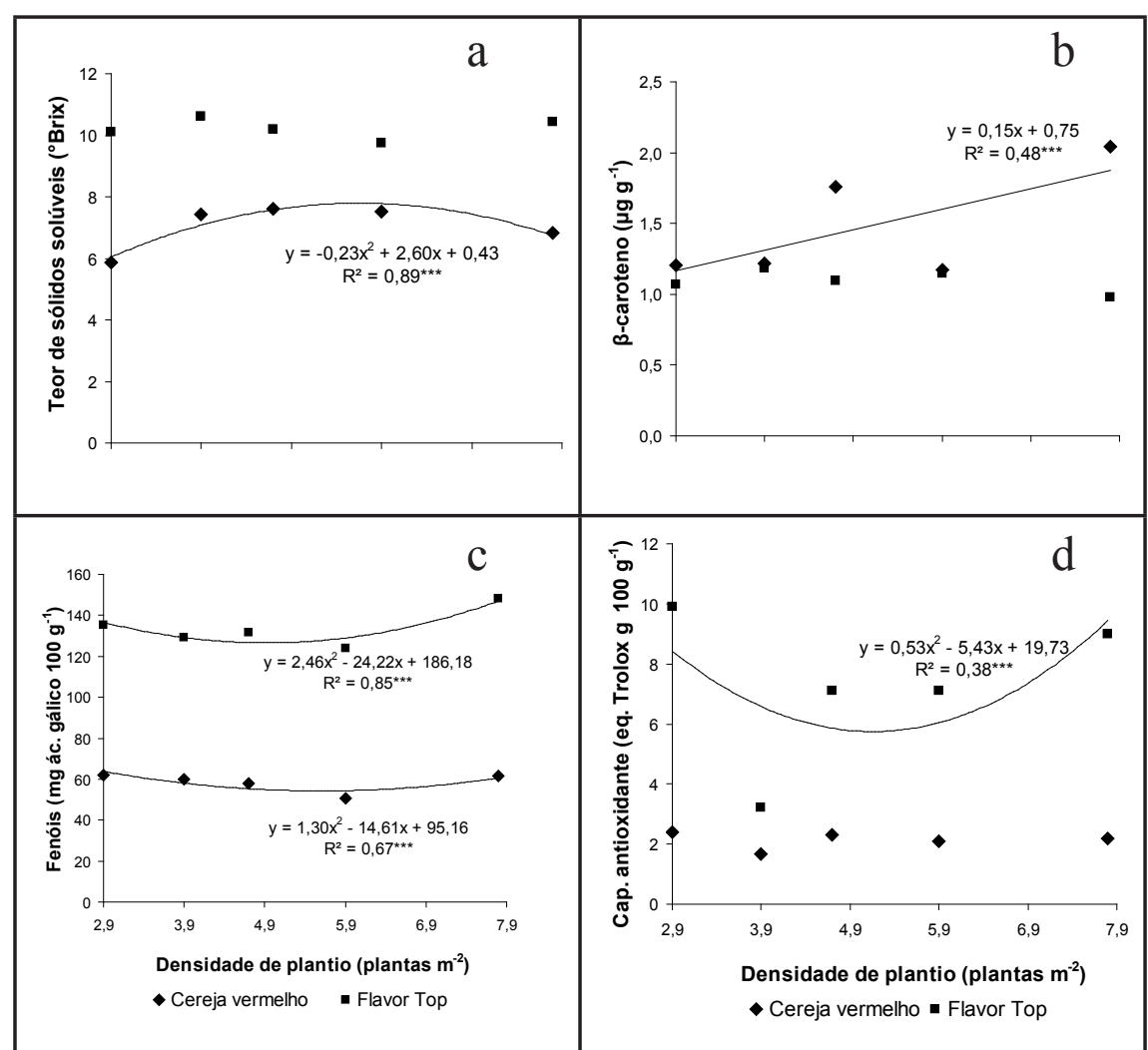

Figura 3. Teor de sólidos solúveis (a) e fitoquímicos [ $\beta$-caroteno (b), fenóis totais (c) e capacidade antioxidante (d)] de frutos de tomateiro dos genótipos 'Cereja Vermelho' e 'Flavor Top' estabelecidos em 5 densidades de plantio e cultivo em substrato de casca de arroz in natura e sistema fechado \{soluble solid content (a) and phytochemicals content $[\beta$-carotene (b), total phenols (c) and antioxidant capacity (d)] of tomato fruits of the genotypes 'Cereja Vermelho' and 'Flavor Top' set at 5 plant densities in raw rice husk closed growing system $\}$. Pelotas, UFPel, 2009.

gar densidades mais elevadas na busca por uma maior produtividade.

Quanto à qualidade de frutos, o aumento da densidade de plantio causou respostas quadráticas no teor de sólidos solúveis totais (TSS; Figura 3a) e no conteúdo de fenóis (Figura 3c), resposta linear positiva no conteúdo de carotenóides (Figura 3b) e não houve resposta na capacidade antioxidante para 'Cereja Vermelho' (Figura 3d). Para os frutos de 'Flavor Top', o teor de fenóis (Figura $3 c)$ e a capacidade antioxidante (Figura 3d) apresentaram respostas quadráticas ao aumento da densidade de plantio. Já, o TSS (Figura 3a) e o conteúdo de carotenóides (Figura 3b) não foram afetados pela variação da densidade. As médias do TSS, da concentração de fenóis e da capacidade antioxidante dos frutos foram significativamente superiores para 'Flavor Top', enquanto que as médias do teor de carotenóides, a partir da densidade de 4,7 plantas $\mathrm{m}^{-2}$, foram condições ambientais mais propícias para o desenvolvimento das plantas.

Quanto à capacidade antioxidante, a curva de resposta (Figura 3d) foi similar à obtida para os compostos fenólicos para 'Flavor Top', por serem estes grandes responsáveis pelo poder antioxidante dos frutos (Lee \& Kader, 2000).

De maneira geral, pode-se concluir que o efeito dos genótipos foi mais marcante sobre as variáveis avaliadas do que o efeito das densidades. 'Cereja Vermelho' apresentou maior alocação de MS nos frutos e, consequentemente, maior crescimento e produtividade. Entretanto, 'Flavor Top' apresentou características fitoquímicas substancialmente mais relevantes e maior concentração de sólidos solúveis. Aliado a isso, o aumento da densidade de plantio entre 2,9 e 7,8 plantas $\mathrm{m}^{-2}$ reduziu o crescimento individual das plantas sem afetar a partição de matéria seca, aumentando a produtividade por unidade de área dos genótipos de tomate cereja.

Considerando os aspectos de crescimento, produtividade e de qualidade dos frutos, bem como a dificuldade de manejo das plantas em cultivos muito adensados, as densidades de plantio de 5,9 plantas $\mathrm{m}^{-2}$ e de 7,8 plantas $\mathrm{m}^{-2}$ são consideradas as melhores, respectivamente, para 'Cereja Vermelho' e 'Flavor Top' no sistema fechado de cultivo em substrato realizado.

\section{AGRADECIMENTOS}

Os autores agradecem à CAPES, ao CNPq e à FAPERGS, pelo auxílio financeiro, e à UFPel, pelo apoio institucional.

\section{REFERÊNCIAS}

Tanto na maior como na menor densidade de plantio ocorreu uma elevação nos teores de compostos fenólicos para ambos os genótipos (Figura 3c). Esse efeito pode ser atribuído ao estresse causado pela competição entre plantas em altas densidades e à proteção contra $\mathrm{a}$ radiação UV em baixas densidades (Lee \& Kader, 2000; Taiz \& Zeiger, 2009). Assim, a alteração da concentração de compostos fenólicos pode ser um parâmetro adicional para determinar as R; BORTOLOTTO OC; LUZ GL. 2004. Crescimento e produtividade de plantas de tomateiro em cultivo protegido sob alta 34: 1251-1253. RS. 2003. Crescimento, desenvolvimento e produtividade do tomateiro cultivado em substrato com três concentrações de nitrogênio na solução nutritiva. Ciência Rural 34: 14511457.

CARRIJO OA; VIDAL MC; REIS NVB; SOUZA
ANDRIOLO JL; ESPÍNOLA MCG; GODÓI densidade e desfolhamento. Ciência Rural

ANDRIOLO JL; WITTER M; ROSS T; GODOI 
RB; MAKISHIMAN. 2004. Produtividade do tomateiro em diferentes substratos e modelos de casas de vegetação. Horticultura Brasileira 22: 05-09.

CARVALHO LA; TESSARIOLI NETO J. 2005. Produtividade de tomate em ambiente protegido, em função do espaçamento e número de ramos por planta. Horticultura Brasileira 23: 986-989.

CASTILLA N. 2001. Manejo del cultivo intensivo con suelo. In: NUEZ F (ed). El cultivo del tomate. Madrid: Ediciones Mundi Prensa. p. 189-225.

COCKSHULL KE; GRAVES CJ; CAVE CRJ. 1992. The influence of shading on yield of glasshouse tomatoes. Journal of Horticulture Science 67: 11-24.

DUARTE TS; PEIL RMN; MONTEZANO EM. 2008a. Crescimento de frutos de meloeiro sob diferentes relações fonte: dreno. Horticultura Brasileira 27: 342-347.

DUARTE TS; PEIL RMN; BACCHI S; STRASSBURGER AS. 2008b. Efeito da carga de frutos e concentrações salinas no crescimento do meloeiro cultivado em substrato. Horticultura Brasileira 27: 348-353.

FERNANDES C; CORÁ JE; BRAZ LT. 2007. Classificação de tomate-cereja em função do tamanho e peso do fruto. Horticultura Brasileira 25: 275-278.

GENÚNCIO GC; MAJEROWICZ N; ZONTA E; SANTOS AM; GRACIA D; AHMED CRM; SILVA MG. 2006. Crescimento e produtividade do tomateiro em cultivo hidropônico NFT em função da concentração iônica da solução nutritiva. Horticultura Brasileira 24: 175-179.

GIMENEZ G; ANDRIOLO JL; GODOI R. 2008. Cultivo sem solo do morangueiro. Ciência Rural 38: 273-279.

HEUVELINK E. 1995. Infuence of sink-source interaction on dry matter production in tomato. Annals of Botany 75: 381-389.

HEUVELINK E. 1997. Effect of fruit load on dry matter partitioning in tomato. Scientia
Horticulturae 69: 51-59.

KALOGEROPOULOS N; CHIOU A; PYRIOCHOU V; PERISTERAKI A; KARATHANOS VT. 2012. Bioactive phytochemicals in industrial tomatoes and their processing byproducts. LWT - Food Science and Technology 49: 213-216.

LASHERAS C; FERNANDEZ S; PATTERSON AM. 2000. Mediterranean diet and age with respect to overall survival in institucionalized, nonsmoking elderly people. American Journal of Clinical Nutrition 71: 987-992.

LEE SK; KADERAA. 2000. Pre-harvest and postharvest factors influencing vitamin content of horticultural crops. Postharvest Biology and Technology 20: 207-220.

LUTHRIA DL; MUKHOPADHYAY S; KRIZEK DT. 2006. Content of total phenolics and phenolic acids in tomato (Lycopersicon esculentum) fruits as influenced by cultivar and solar UV radiation. Journal of Food and Analysis 19: 771-777.

MOTA FS; BEIRSDORF MIC; ACOSTA MJ. 1986. Estação Agroclimática de Pelotas: Realizações e programa de trabalho. Pelotas: UFPel.

PAPADOPOULOS AP; PARARAJASINGHAM S. 1997. The influence of plant spacing on light interception and use in greenhouse tomato (Lycopersicon esculentum): A review. Scientia Horticulturae 69: 1-29.

PEIL RMN; BOONYAPORN S; SAKUMA H. 1994. Effect of different kind of media on the growth of tomato in soilless culture. Report on Experiments of Vegetable Crops Productin Course of TIATC, 67-73.

PEIL RMN; GÁLVEZ JL. 2005. Reparto de materia seca como factor determinante de la producción de las hortalizas de fruto cultivadas en invernadero. Revista Brasileira de Agrociência 11: 05-11.

RADIN B; BERGAMASCHI H; REISSER JÚNIOR C; BARNI NA; MATZENAUER R; DIDONÉ IA. 2003. Eficiência de uso da radiação fotossinteticamente ativa pela cultura do tomateiro em diferentes ambientes. Pesquisa Agropecuária Brasileira 38: 1017. 1023.

RE R; PELLEGRINI N; PROTEGGENTE A; PANNALA A; YANG M; RICE-EVANS C. 1999. Antioxidant activity applying an improved ABTS radical cation decolorization assay. Free Radical Biology and Medicine 26: 1231-1237.

ROCHA MQ. 2009. Crescimento, Fenologia e Rendimento do tomateiro cereja em cultivo hidropônico. Pelotas: UFPEL. 129p. (Tese mestrado).

ROCHA MQ; PEIL RMN; COGO CM. 2010. Rendimento do tomate cereja em função do cacho floral e da concentração de nutrientes em hidroponia. Horticultura Brasileira 28: 466-471.

RODRIGUEZ-AMAYA DB. 1999. A guide to carotenóids analysis in foods. Washington: ILSI Press. 64p.

SELEGUINI A; SENO S; ZIZAS GB. 2002. Influência do espaçamento entre plantas e número de cachos por planta na cultura do tomateiro em condições de ambiente protegido. In: CONGRESSO BRASILEIRO DE OLERICULTURA, 42. Resumos... Uberlândia: SOB (CD-ROM).

SINGLETON VL; ROSSI JJR. 1965. Colorimetry of total phenolics with phosphomolybdicphosphotungstic acid reagents. American Journal of Enology and Viticulture 16:144158.

STAUSS, H. 2008. WinStat Manual. Doing Statistics with WinStat. Disponível em http:// haraldstauss.com/HaraldStaussScientific/ products/WinStat.pdf.

STRASSBURGER AS; PEIL RMN; FONSECA LA; AUMONDE TZ; MAUCH CR. 2011. Dinâmica do crescimento da abobrinha italiana em duas estações de cultivo. Acta Scientiarum 33: 283-289.

TAIZ L; ZEIGER E. 2009. Fisiologia vegetal. 4 ed. Porto Alegre: Artmed. 819p. 